\title{
Interactions of vanadates with carbohydrates in aqueous solutions
}

\author{
Ana C.F. Ribeiro*, Artur J.M. Valente, Victor M.M. Lobo, Eduarda F.G. Azevedo, \\ Ana M. Amado, A.M. Amorim da Costa, M. Luísa Ramos, H.D. Burrows \\ Department of Chemistry, University of Coimbra, 3004-535 Coimbra, Portugal
}

Received 30 March 2004; revised 11 May 2004; accepted 11 May 2004

\begin{abstract}
The interaction between the vanadate ion $\left(\mathrm{VO}_{3}^{-}\right.$, i.e. vanadium $\left.(\mathrm{V})\right)$ and the carbohydrates sucrose, glucose and fructose has been studied in aqueous solutions ( $\mathrm{pH} \approx 6,298.15 \mathrm{~K}$ ) using measurements of diffusion coefficients, electrical conductivity, Raman and multinuclear NMR spectroscopy. With sucrose and glucose, indications of hydrolysis of the anion in the absence of the sugars came from a decrease in the diffusion coefficient with increasing concentration. Significant effects on the diffusion coefficients were observed in the presence of sucrose and glucose, suggesting interactions between the carbohydrates and vanadate ion. Support for this came from electrical conductivity measurements, where there were indications of formation of oligomeric species. These were found to depend on the carbohydrate used: confirmation of oligomer formation came from Raman spectroscopy, where it was possible to identify these species, and see their dependence on the particular carbohydrate used. Information on the interactions between the carbohydrates glucose or sucrose and vanadate came from ${ }^{51} \mathrm{~V}$ and ${ }^{1} \mathrm{H}$ NMR spectroscopy, where the dominant species appeared to be a 2:2 complex with glucose, possessing trigonal bipyramidal centres, whereas with sucrose it is suggested that octahedral species are formed. Studies with fructose were complicated by competing oxidation of this carbohydrate and reduction of vanadium $(\mathrm{V})$.
\end{abstract}

(C) 2004 Elsevier B.V. All rights reserved.

Keywords: Diffusion; Electrolytes; Transport properties; Sucrose; Carbohydrates

\section{Introduction}

Although vanadium is a trace element, it has considerable biological relevance due to the great similarity between its chemistry and that of phosphate [1,2]. Vanadium salts display insulin-like activity and may be used in the treatment of diabetes [2]. In addition, they may induce cardiovascular and hormonal activity, and affect the activity of several enzymes. However, at high concentrations they may be toxic due to alterations on the enzyme activity responsible for phosphate metabolism.

Vanadium is commonly present in such systems as vanadium $(\mathrm{V})$ in the form of the vanadate anion. Vanadate aqueous solutions consist of a complex mixture of different oligomers ( $V_{n}$, where $\mathrm{n}$ is the number of vanadium centers, see Fig. 1) with different states of protonation and, in some

\footnotetext{
* Corresponding author. Tel.: +351-239-828403; fax: +351-239827703.

E-mail addresses: anacfrib@ci.uc.pt (A.C.F. Ribeiro), avalente@ci.uc. pt (A.J.M. Valente), vlobo@ci.uc.pt (V.M.M. Lobo), ama1@portugalmail. pt (A.M. Amado), acosta@ci.uc.pt (A.M.A. da Costa), mlramos@ci.uc.pt (M.L. Ramos), burrows@ci.uc.pt (H.D. Burrows).
}

cases, with different forms (linear, L, or cyclic, C) $[3,4]$. According to several studies, in the concentration range used in this work $(1-80 \mathrm{mM})$ and $\mathrm{pH}$ value $(\approx 6)$ the main species are shown in Fig. 1.

Although several studies involving the interaction of vanadate with small molecules (e.g. methanol and ethanol) have been carried out in the last decade, no data are available on the diffusion coefficients of ammonium monovanadate in model biological environments. The present paper intends to fill this gap, and reports experimental data for vanadium (V) in aqueous solutions of sucrose, glucose and fructose at 298.15 K. These studies are complemented by Raman and nuclear magnetic resonance (NMR) spectroscopic studies and conductance measurements to attempt to identify the dominant species involved in the diffusion processes.

\section{Experimental}

\subsection{Reagents}

The solutes used in this study were ammonium monovanadate (Merck, pro analysi, >99\%), sucrose 


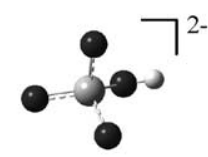

HV1

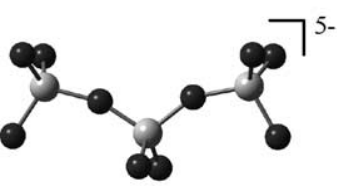

V3L

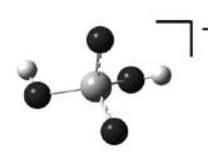

$\mathrm{H}_{2} \mathrm{~V} 1$

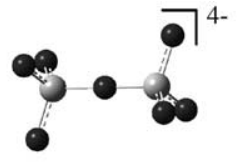

V2

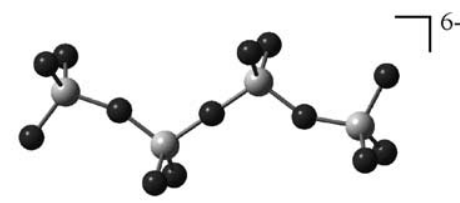

V4L

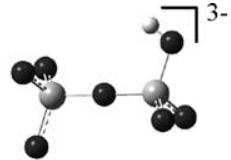

HV2

Fig. 1. Schematic structures of the main species in vanadate aqueous solutions (adapted from $\mathrm{Ref}[3,4]) \mathrm{HVO}_{4}^{2-}(\mathrm{HV}), \mathrm{H}_{2} \mathrm{VO}_{4}^{-}\left(\mathrm{H}_{2} \mathrm{~V}\right), \mathrm{V}_{2} \mathrm{O}_{7}^{4-}(\mathrm{V} 2)$, $\mathrm{HV}_{2} \mathrm{O}_{7}^{3-}(\mathrm{HV} 2), \mathrm{V}_{3} \mathrm{O}_{10}^{5-}(\mathrm{V} 3 \mathrm{~L}), \mathrm{V}_{4} \mathrm{O}_{13}^{6-}(\mathrm{V} 4 \mathrm{~L})$ and $\mathrm{V}_{4} \mathrm{O}_{12}^{4-}(\mathrm{V} 4 \mathrm{c})$.

(Sigma, pro analysi $>99 \%)$, D(-)-fructose (Riedel-deHaën, Chem. pure) and D(+)-glucose (Sigma, >97\%). These were used without further purification. Aqueous solutions were prepared using bi-distilled (diffusion measurements and Raman spectroscopy) and Millipore (conductance measurements) water, and $\mathrm{D}_{2} \mathrm{O}(\mathrm{SdS}$, pro analysi, $>99.90 \%$ ) NMR spectroscopy. All solutions were freshly prepared before each experiment.

\subsection{Diffusion measurements}

Diffusion coefficients were measured with an open-ended capillary cell. The apparatus assembled for use with the open-ended capillary cell in this laboratory is essentially the same as previously reported [5]. The cell has two vertical capillaries, each closed at one end by a platinum electrode and positioned one above the other with the open ends separated by a distance of about $14 \mathrm{~mm}$.

The upper and lower tubes, initially filled with solutions of concentrations 0.75 and $1.25 c$, respectively, were surrounded with a solution of concentration $c$. This ambient solution was contained in a glass tank $(200 \times 140 \times 60) \mathrm{mm}$ immersed in a thermostat at $298.15 \mathrm{~K}$. The tank was divided internally by Perspex sheets and a glass stirrer created a slow lateral flow of ambient solution across the open ends of the capillaries. Experimental conditions were such that the concentration at each of the open ends was equal to the ambient solution value $c$, that is the physical length of the capillary tube coincided with the diffusion path, such that the boundary conditions described in the literature [5] to solve Fick's second law of diffusion are applicable. As a consequence, the so-called $\Delta$ l-effect [5] is reduced to negligible proportions. In contrast to a manual apparatus, where diffusion is followed by measuring the ratio of resistances of the top and bottom tubes, $w=R_{\mathrm{t}} / R_{\mathrm{b}}$, by an alternating current transformer bridge, in our automatic apparatus w was measured by a Solartron digital voltmeter (DVM) 7061 with 6 1/2 digits. A Bradley Electronics Model
232 power source supplied a $30 \mathrm{~V}$ sinusoidal signal of $4 \mathrm{kHz}$ (stable up to $0.1 \mathrm{mV}$ ) to a potential divider that applied a $250 \mathrm{mV}$ signal to the platinum electrodes at the top and bottom capillaries. By rapidly $(<1 \mathrm{~s})$ measuring the voltages $V^{\prime}$ and $V^{\prime \prime}$ from top and bottom electrodes to the central electrode at ground potential, the value $w=R_{\mathrm{t}} / R_{\mathrm{b}}$ was then calculated from the DVM reading.

To measure the differential diffusion coefficient, $D$, at a given concentration $c$, a 'top' solution of concentration 0.75 $c$ and a 'bottom' solution of concentration $1.25 c$ were prepared, each in a 2 L volumetric flask. The 'bulk' solution of concentration $c$ was produced by mixing accurately measured volumes of $1 \mathrm{~L}$ of 'top' solution with $1 \mathrm{~L}$ of 'bottom' solution. The ammonium monovanadate solutions were prepared by heating to $353.15 \mathrm{~K}$ and then allowing them to cool to $298.15 \mathrm{~K}$. The glass tank and the two capillaries were filled with solution $c$, immersed in the thermostat, and were allowed to come to thermal equilibrium. The quantity $\mathrm{TR}_{\text {inf }}=10^{4} /(1+w)$ was now measured very accurately. Here $w=R_{\mathrm{t}} / R_{\mathrm{b}}$ is the electrical resistance $(\mathrm{R})$ ratio for solutions of concentration $c$ of the top (t) and bottom (b) diffusion capillaries at infinite time. $\mathrm{TR}=10^{4} /(1+w)$ is the equivalent at any time $t$.

The capillaries were then filled with 'top' and 'bottom' solutions, which were allowed to diffuse into the 'bulk' solution. Resistance ratio readings were taken at recorded times, beginning 1000 min after the start of each experiment. The diffusion coefficient was evaluated using a linear least-squares procedure to fit the data, followed by an iterative process which uses 20 terms of the expansion series of the solution of Fick's second law for the present boundary conditions. The theory developed for this cell has been described previously [5].

\subsection{Conductance measurements}

Solution electrical resistances were measured with a Wayne-Kerr model 4265 Automatic LCR meter at $1 \mathrm{kHz}$. 
A Shedlovsky-type conductance cell was used. Cell constants (approx. $0.1417 \pm 0.0001 \mathrm{~cm}^{-1}$ ) were determined from measurements with $\mathrm{KCl}$ (reagent grade, recrystallized, and dried) using the procedure and data of Barthel et al. [6]. Measurements were made at $298.15 \pm 0.01 \mathrm{~K}$. All solutions were prepared using Millipore water. Solutions were always used within $12 \mathrm{~h}$ after preparation. In a typical experiment a carbohydrate solution (around $0.001 \mathrm{M})$, prepared with Millipore water $(\kappa=0.7$ to $0.9 \times 10^{-4} \Omega^{-1} \mathrm{~m}^{-1}$ ) was placed in the conductivity cell, thermostated to the desired temperature and the conductance of the solution was measured. Then, known amounts of the vanadium solution were added in a stepwise manner using a micropipette. The analysed vanadium concentration range was $6 \times 10^{-4}$ to $2 \times 10^{-2} \mathrm{M}$. The conductance of the solution was measured after each addition.

\subsection{Raman spectral measurements}

Raman spectra were recorded on a Jobin-Yvon T64000 triple monochromator Raman system (focal length $0.640 \mathrm{~m}$, aperture f/7.5) with a nonintensified CCD detector. The excitation source was a Spectra-Physics Argon ion laser, the output of which at $514.4 \mathrm{~nm}$ was adjusted to provide $90-100 \mathrm{~mW}$ at the sample position. The sample solutions were kept in a cylindrical cell of internal diameter $c a .6 \mathrm{~mm}$.

Special attention was given to the $760-1050 \mathrm{~cm}^{-1}$ spectral region, as this was previously shown to be very sensitive to the oligomeric equilibrium of vanadium (V) in aqueous solutions [3]. Each spectrum is an average of 10-20 cycles, depending on the solution vanadium concentration, of 15 scans recorded with an integration time of up to $60 \mathrm{~s}$.

\subsection{NMR measurements}

The solutions were prepared by weighting of the appropriate amounts of the vanadium salt and glucose, sucrose or fructose, using $\mathrm{D}_{2} \mathrm{O}$ as solvent. The $\mathrm{pH}$ was adjusted (cautiously, to reduce the possibility of drastic local disturbances of equilibria that may be slow to disappear) by addition of $\mathrm{DCl}$ and $\mathrm{NaOD}$; the $\mathrm{pH}^{*}$ values quoted are the direct $\mathrm{pH}$-meter readings (at room temperature) after standardization with aqueous (water) buffers.

The ${ }^{1} \mathrm{H},{ }^{13} \mathrm{C}$ and ${ }^{51} \mathrm{~V}$ NMR spectra were obtained on a Varian UNITY-500 NMR spectrometer (at 499.824, 125.692 and $131.404 \mathrm{MHz}$, respectively). The ${ }^{1} \mathrm{H}$ NMR spectra were recorded using spectral widths of $5000 \mathrm{~Hz}$, acquisition times of $5 \mathrm{~s}$, pulse delays of $5 \mathrm{~s}$ and about 320 pulses. The residual water signal was reduced by using the Presat sequence. The ${ }^{13} \mathrm{C}$ NMR spectra were obtained using proton-decoupling techniques with suppression of the nuclear Overhauser effect, spectral widths of $30,000 \mathrm{~Hz}$, acquisition times of $1 \mathrm{~s}$, pulse delays of $10 \mathrm{~s}$ and about 5000 pulses. The methyl signal of $t$-butyl alcohol was used as internal reference for ${ }^{1} \mathrm{H}(\delta=1.3)$ and ${ }^{13} \mathrm{C}(\delta=31.2)$, using the chemical shift values in brackets relative to TMS. The ${ }^{51} \mathrm{~V}$ NMR spectra were obtained using $\operatorname{VOCl}_{3}(\delta=0)$ as external reference, with typically, spectral widths of $80,000 \mathrm{~Hz}$, acquisition times of $0.04 \mathrm{~s}$, pulse delays of $0.02 \mathrm{~s}$ and about 16,000 pulses.

\section{Results and discussion}

3.1. Diffusion coefficients of $\mathrm{NH}_{4} \mathrm{VO}_{3}$ in aqueous solutions of sucrose, fructose and glucose

Table 1 and Fig. 2 show the experimental diffusion coefficients with ammonium monovanadate solutions from $1 \times 10^{-3}$ to $5 \times 10^{-2} \mathrm{M}$ at $298.15 \mathrm{~K}$ alone, and in the presence of sucrose, fructose and glucose. These results are the average of three experiments performed on consecutive days. Good reproducibility was observed, as seen by the small standard deviations of the mean, $S_{\text {Dav }}$. Previous papers [7-15] reporting data obtained with our conductivity cell have shown that the inaccuracy of our results should be close to the imprecision, therefore giving an experimental uncertainty $1-2 \%$.

The experimental diffusion coefficients shown in Fig. 2 can be fitted using a polynomial equation

$D=a_{0}+a_{1} c^{1 / 2}+a_{2} c+a_{3} c^{3 / 2}$

where the coefficients $a_{0}, a_{1}, a_{2}$ and $a_{3}$ are adjustable parameters.

The fits to the experimental data points were obtained using the mean square deviation method; the goodness of the fit can be assessed by the correlation coefficient $\left(R^{2}\right)$, using a $95 \%$ confidence interval. Table 2 shows the coefficients $a_{0}$ to $a_{3}$ of Eq. (1). They may be used to calculate values of diffusion coefficients at specified concentrations within the range of the experimental data.

From Table 1 and Fig. 2, the decrease of the diffusion coefficient of ammonium monovanadate in aqueous solutions with increasing concentration strongly suggests

Table 1

Diffusion coefficients, $D$, of $\mathrm{NH}_{4} \mathrm{VO}_{3}$ in aqueous solutions at $298.15 \mathrm{~K}$ at different concentrations, $c$ (see Ref. [14])

\begin{tabular}{llll}
\hline$c / M$ & $D /\left(10^{-9} \mathrm{~m}^{2} \mathrm{~s}^{-1}\right)^{\mathrm{a}}$ & TRinf $^{\mathrm{b}}$ & $S_{\text {Dav }} / 10^{-9} \mathrm{~m}^{2} \mathrm{~s}^{-1 \mathrm{c}}$ \\
\hline 0.001 & 1.264 & 5000.5 & 0.018 \\
0.003 & 1.203 & 4999.8 & 0.009 \\
0.005 & 1.174 & 5000.0 & 0.003 \\
0.008 & 1.147 & 5000.1 & 0.006 \\
0.010 & 1.135 & 5000.2 & 0.010 \\
0.020 & 1.116 & 5010.0 & 0.008 \\
0.030 & 1.110 & 5011.1 & 0.007 \\
0.050 & 1.090 & 4995.5 & 0.008 \\
\hline
\end{tabular}

${ }^{\text {a }}$ Mean value of $D_{\text {exp }}$. in three experiments.

b TRinf $=10^{4} /(1+w)$, where $w=R_{\mathrm{t}} / R_{\mathrm{b}}$ is the resistance ratio of top and bottom capillaries.

c $S_{\mathrm{Dav}}$ is the standard deviation of the mean of three experiments. 

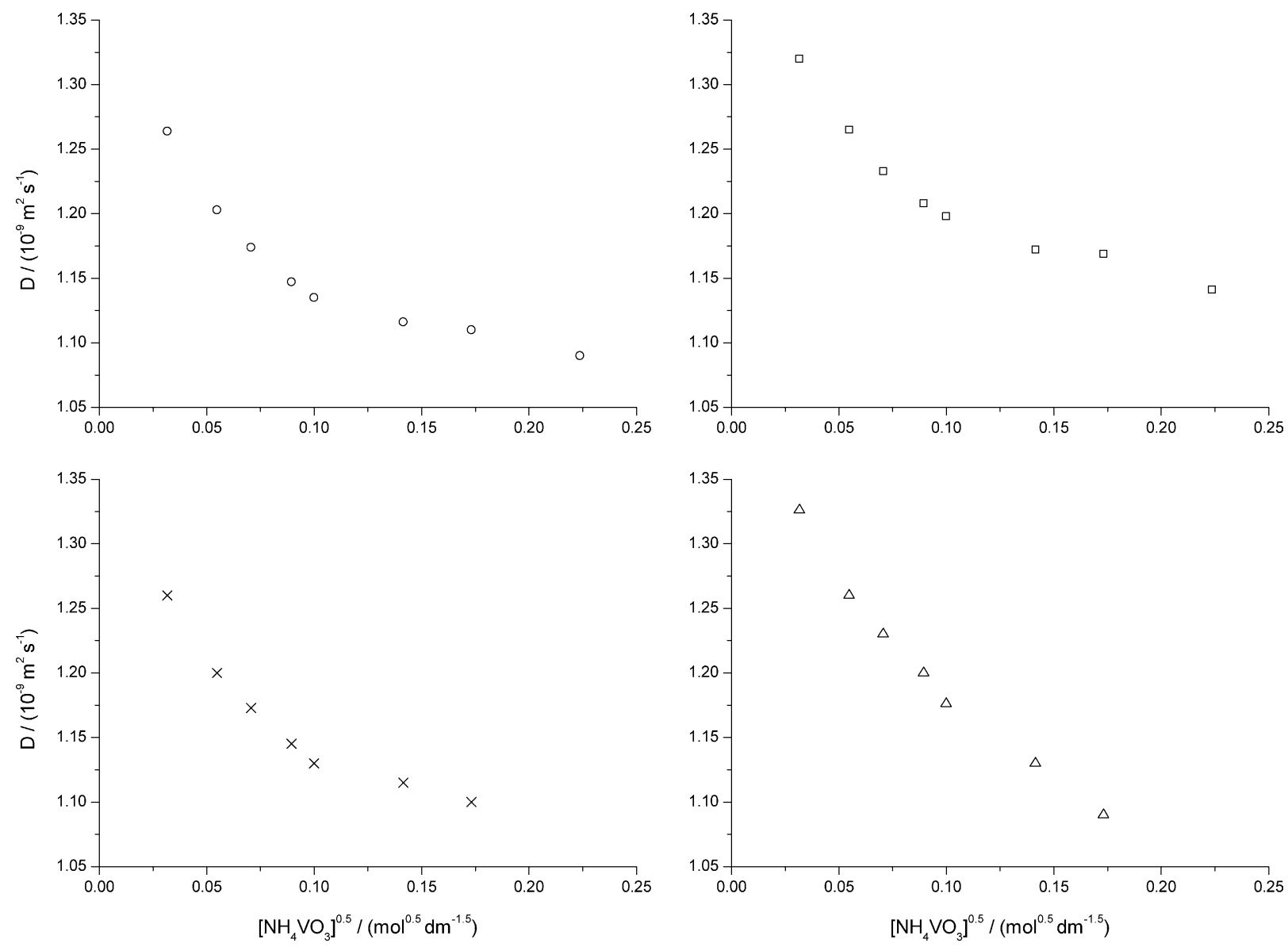

Fig. 2. Diffusion coefficients, $D$, of ammonium monovanadate in aqueous solutions $(\bigcirc)$, and in aqueous solutions of fructose ( $\times$ ) $1 \mathrm{mM}$, sucrose $(\square) 1 \mathrm{mM}$ and glucose $(\triangle) 1 \mathrm{mM}$

the presence of new species (e.g. $\mathrm{V}_{4} \mathrm{O}_{12}^{4-}$ ) resulting from condensation of the anion. The decrease of $D$ with concentration may be explained by assuming those species have a lower mobility than other anions (i.e. a probable mixture of $\mathrm{V}_{x} \mathrm{O}_{3 x}^{x-}$ anions including possibly $\mathrm{VO}_{3}^{-}$), because of their size. The eventual formation of ion pairs, increasing with concentration may also contribute to the decrease of $\mathrm{D}$ with concentration [14].

Sucrose and glucose exert a significant influence on the diffusion of ammonium monovanadate in the different aqueous solutions $(c \leq 0.05$ and $c \leq 0.01 \mathrm{M}$, respectively). In contrast, for $0.001 \mathrm{M}$ fructose, the diffusion behaviour of ammonium monovanadate appears to be the same in the absence or the presence of those molecular anions.

This behaviour can be explained considering the different interactions (coulombic, etc.) between the carbohydrate molecules and the monovanadate anion that can influence the degree of hydration. Support for a decrease in hydration comes from calculations of the effect of sucrose on the potential of mean force between sodium and chloride ions in aqueous solutions [16], where addition of sucrose has shown

Table 2

Fitting coefficients $\left(a_{0}-a_{3}\right)$ of a polynomial equation to the mutual differential diffusion coefficients of ammonium monovanadate in aqueous solutions and in aqueous solutions of $0.001 \mathrm{M}$ sucrose, fructose and glucose. The different coefficients should be read as: $D\left(\mathrm{~m}^{2} \mathrm{~s}^{-1}\right)=a_{0}+a_{1}(\mathrm{c} / \mathrm{M})^{1 / 2}+a_{2}(\mathrm{c} / \mathrm{M})+a_{3}(\mathrm{c} / \mathrm{M})^{3 / 2}$

\begin{tabular}{llllr}
\hline Carbohydrate & $a_{0}\left(10^{-9}\right)$ & $a_{1}\left(10^{-9}\right)$ & $a_{2}\left(10^{-8}\right)$ & $R_{3}^{2}\left(10^{-8}\right)$ \\
\hline Without $^{\mathrm{a}}$ & $1.388( \pm 0.003)$ & $-4.725( \pm 0.094)$ & $2.776( \pm 0.083)$ & $-5.628( \pm 0.216)$ \\
Sucrose $^{\mathrm{a}}$ & $1.438( \pm 0.006)$ & $-4.460( \pm 0.202)$ & $2.587( \pm 0.179)$ & 0.999 \\
Frutose $^{\mathrm{b}}$ & $1.386( \pm 0.014)$ & $-4.826( \pm 0.549)$ & $2.971( \pm 0.609)$ & 0.999 \\
Glucose $^{\mathrm{b}}$ & $1.444( \pm 0.015)$ & $-4.461( \pm 0.570)$ & $2.403( \pm 0.633)$ & 0.998 \\
\hline
\end{tabular}

\footnotetext{
${ }^{\mathrm{a}} c \leq 0.05 \mathrm{M}$.

${ }^{\mathrm{b}} c \leq 0.03 \mathrm{M}$.
} 
to decrease the number of water molecules in the first hydration sphere of the ions.

For the present experimental conditions, i.e. pseudobinary systems and dilute solutions, the motion of the solvent and the change of parameters such as viscosity, dielectric constant and degree of hydration with concentration, can be neglected. The interpretation of the behaviour of diffusion of those systems can be then made on the basis of Onsager-Fuoss model [17], suggesting that $D$ is a product of both kinetic (molar mobility coefficient of a diffusing substance, $U_{\mathrm{m}}$ ) and thermodynamic factors ( $c \delta \mu / \delta c$, where $\mu$ represents the chemical potential). With this simple model, these interactions can be responsible for the increase of the free energy gradient and consequently, larger diffusion coefficients. In the present case, the major contribution to the change in $D$ may be attributed to the nonideality in behaviour of the thermodynamic factor. From the similar conductance behaviour of ammonium monovanadate observed in the presence and absence of sucrose or glucose (see Fig. 2), changes in the mobility factor with concentration do not appear to be relevant.

For the case of $0.001 \mathrm{M}$ fructose, the diffusion of $\mathrm{NH}_{4} \mathrm{VO}_{3}$ in aqueous solutions does not appear to be
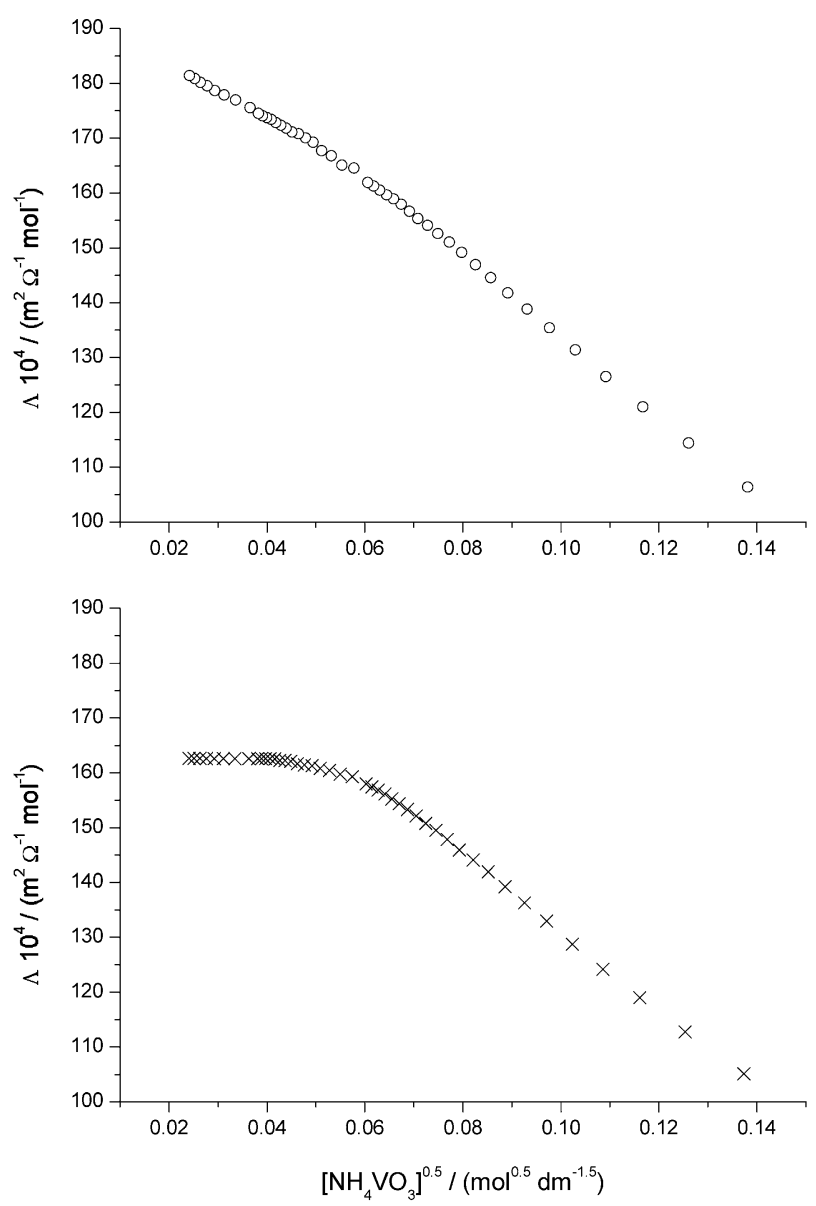

affected, possibly because of two opposing effects: (i) decreasing of the mobility of $\mathrm{NH}_{4} \mathrm{VO}_{3}$ (see Fig. 2); (ii) increasing the gradient of the free energy with concentration. In addition, as will be discussed later, fructose reduces vanadium $(\mathrm{V})$, leading to changes in the chemical composition of the system.

\subsection{Conductivity measurements}

Conductivity results are shown in Fig. 3. From this figure, there appear to be two distinct linear relationships between the molar conductivity and the square root of initial concentration of monovanadate above and below an inflexion point. Support comes from the very good correlation coefficients for fitting the experimental results to a linear equation (Table 3), using the square mean deviation methods and a confidence degree of $95 \%$. This is very similar to what is observed with surfactants [18], which has been justified in terms of a pseudo phase transition involving aggregate formation. In the present case, we suggest that the change involves formation of oligomeric vanadium (V) species. Consequently, the concentration at which conductivity properties will change, which we call
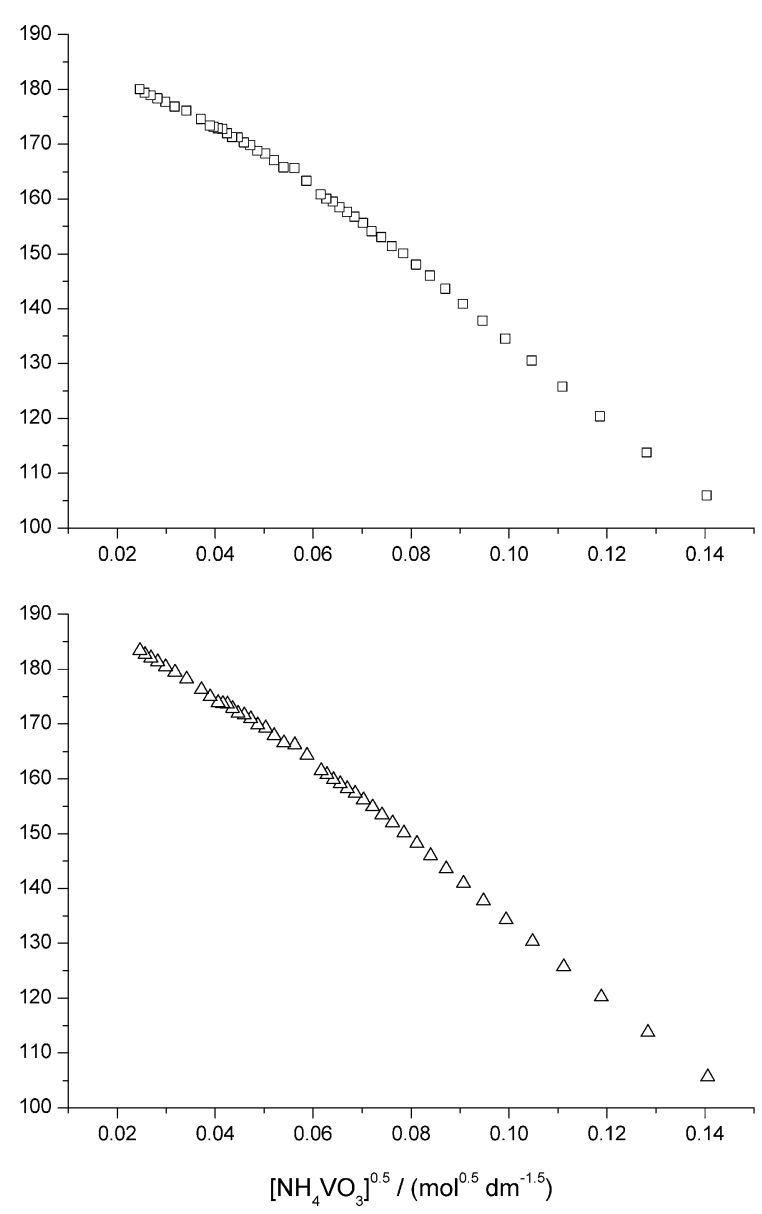

Fig. 3. Molar conductivity, $\Lambda$, of ammonium monovanadate in aqueous solutions ( $\bigcirc$ ), and in aqueous solutions of fructose ( $\times$ ) $1 \mathrm{mM}$, sucrose $(\square) 1 \mathrm{mM}$ and glucose $(\triangle) 1 \mathrm{mM}$. 
Table 3

Parameters computed from fitting Eq. $\Lambda=A-B(c)^{1 / 2}$ to the experimental data shown in Fig. 3, and coc (pg. 6) of ammonium monovanadate in aqueous solutions with and without carbohydrates

\begin{tabular}{|c|c|c|c|c|}
\hline$\Delta c(\mathrm{mM})$ & $A(s)\left(\Omega^{-1} \mathrm{jm}^{2}\right)$ & $B(s) /\left(\mathrm{mol}^{-0.5} \mathrm{~m}^{1.5}\right)$ & $R^{2}$ & $\operatorname{coc}(s)(\mathrm{mM})$ \\
\hline \multicolumn{5}{|l|}{$\mathrm{H}_{2} \mathrm{O}$} \\
\hline $0.587-2.45$ & $\begin{array}{l}192.9 \\
(0.113)\end{array}$ & $\begin{array}{l}478.1 \\
(2.967)\end{array}$ & 1.000 & $\begin{array}{l}3.231 \\
(0.001)\end{array}$ \\
\hline $4.15-19.1$ & $\begin{array}{l}207.7 \\
(0.318)\end{array}$ & $\begin{array}{l}738.8 \\
(3.494)\end{array}$ & 1.000 & \\
\hline \multicolumn{5}{|l|}{ Sucrose } \\
\hline $0.606-2.10$ & $\begin{array}{l}190.7 \\
(0.311)\end{array}$ & $\begin{array}{l}438.0 \\
(9.214)\end{array}$ & 0.998 & $\begin{array}{l}2.835 \\
(0.001)\end{array}$ \\
\hline $3.79-19.7$ & $\begin{array}{l}205.4 \\
(0.345)\end{array}$ & $\begin{array}{l}712.6 \\
(3.876)\end{array}$ & 1.000 & \\
\hline \multicolumn{5}{|l|}{ Glucose } \\
\hline $0.608-2.11$ & $\begin{array}{l}197.2 \\
(0.290)\end{array}$ & $\begin{array}{l}564.2 \\
(7.910)\end{array}$ & 0.998 & $\begin{array}{l}3.531 \\
(0.002)\end{array}$ \\
\hline $3.95-19.6$ & $\begin{array}{l}206.8 \\
(0.345)\end{array}$ & $\begin{array}{l}725.9 \\
(3.816)\end{array}$ & 1.000 & \\
\hline \multicolumn{5}{|l|}{ Fructose } \\
\hline $0.580-15.8$ & $\begin{array}{l}162.6 \\
(0.002)\end{array}$ & $\begin{array}{l}1.353 \\
(0.074)\end{array}$ & 0.987 & $\begin{array}{l}3.084 \\
\left(4 \times 10^{-4}\right)\end{array}$ \\
\hline $3.93-18.8$ & $\begin{array}{l}202.0 \\
(0.390)\end{array}$ & $\begin{array}{l}711.2 \\
(4.361)\end{array}$ & 1.000 & \\
\hline
\end{tabular}

the critical oligomeric concentration (coc), can be determined by the intersection of the two straight lines in the conductivity-concentration plots above and below the coc [19]. The calculated results are shown in Table 3.

The coc found for the different systems are in complete agreement with evidence for oligomer formation from Raman spectroscopy, as discussed in Section 3.3, and does not depend significantly on the type of saccharides. There may be a slight decrease in the coc in systems containing sucrose, but this is probably due to the increasing size of the carbohydrate structure.

The most notable finding occurs with aqueous solutions of ammonium monovanadate in the presence of fructose, where the molar conductivity, at concentrations below coc, is clearly fructose dependent, and almost constant. However, fructose is a reducing sugar, and from Raman and NMR studies it is possible to see that it can reduce $\mathrm{V}(\mathrm{V})$ to $\mathrm{V}(\mathrm{IV})$, which cannot be seen in the diffusion or conductivity measurements. Similar reduction process does not occur in other systems.

\subsection{Raman spectra of $\mathrm{NH}_{4} \mathrm{VO}_{3}$ in aqueous solutions of sucrose, fructose and glucose}

The Raman spectra results are shown in Figs. 4 and 5, and Table 4. The speciation of aqueous vanadate solutions involves complex equilibria between various mono- and oligonuclear vanadium species, which differ in the degree of protonation and/or molecular form (linear or cyclic). The composition of the solutions critically depends on

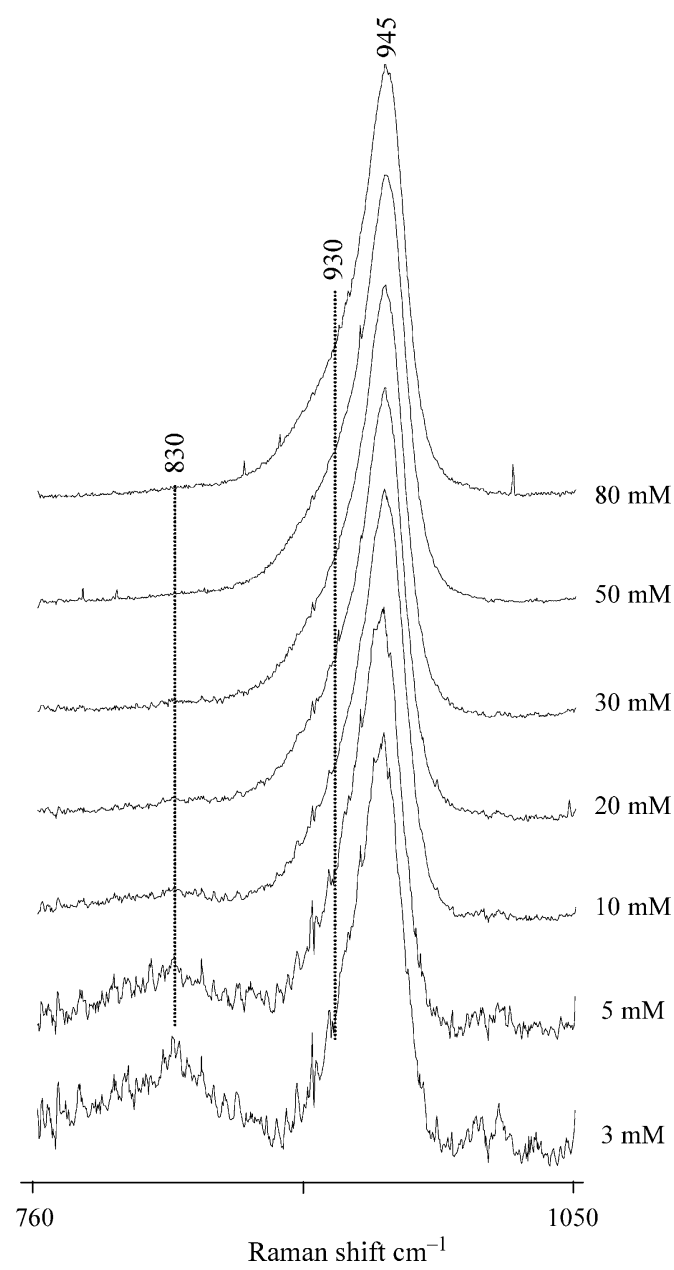

Fig. 4. Partial Raman Spectra, in the $760-1050 \mathrm{~cm}^{-1}$ spectral region, of vanadate-water-sucrose $([$ sucrose $]=1.0 \mathrm{mM})$ as a function of vanadate total concentration.

both the total vanadate concentration and the solution $\mathrm{pH}$ [3,20,21].

According to earlier studies [3,20], in the vanadium concentration range $3-80 \mathrm{mM}$ around $\mathrm{pH} 6$, the main species are: mono- and di-protonated monovanadate, HV1 and $\mathrm{H} 2 \mathrm{~V} 1$, respectively, the divanadate and its monoprotonated form, V2 and HV2, respectively, the trimeric linear form, V3L and the tetrameric linear and cyclic forms, V4L and V4C, respectively (Fig. 1).

From previous Raman and ${ }^{51} \mathrm{~V}$ NMR studies on the speciation of aqueous vanadate solutions of two different vanadium total concentrations, 50 and $100 \mathrm{mM}$, at different $\mathrm{pH}$ values [3], it has been shown (see Table 4) that the least polymerized species HV1, H2V1 and V2 are associated with an extremely broad Raman band in the $770-890 \mathrm{~cm}^{-1}$ spectral region. The other vanadate species were found to show a very intense, asymmetric band, which is centred at $945 \mathrm{~cm}^{-1}$ for $\mathrm{HV} 2$, while the linear V3L and V4L species are associated with a shoulder occurring in the lowfrequency side of this $945 \mathrm{~cm}^{-1}$ band $\left(c a ., 930 \mathrm{~cm}^{-1}\right)$.

Fig. 4 shows the partial Raman spectra (760$1050 \mathrm{~cm}^{-1}$ ) of aqueous vanadate solutions, of different 

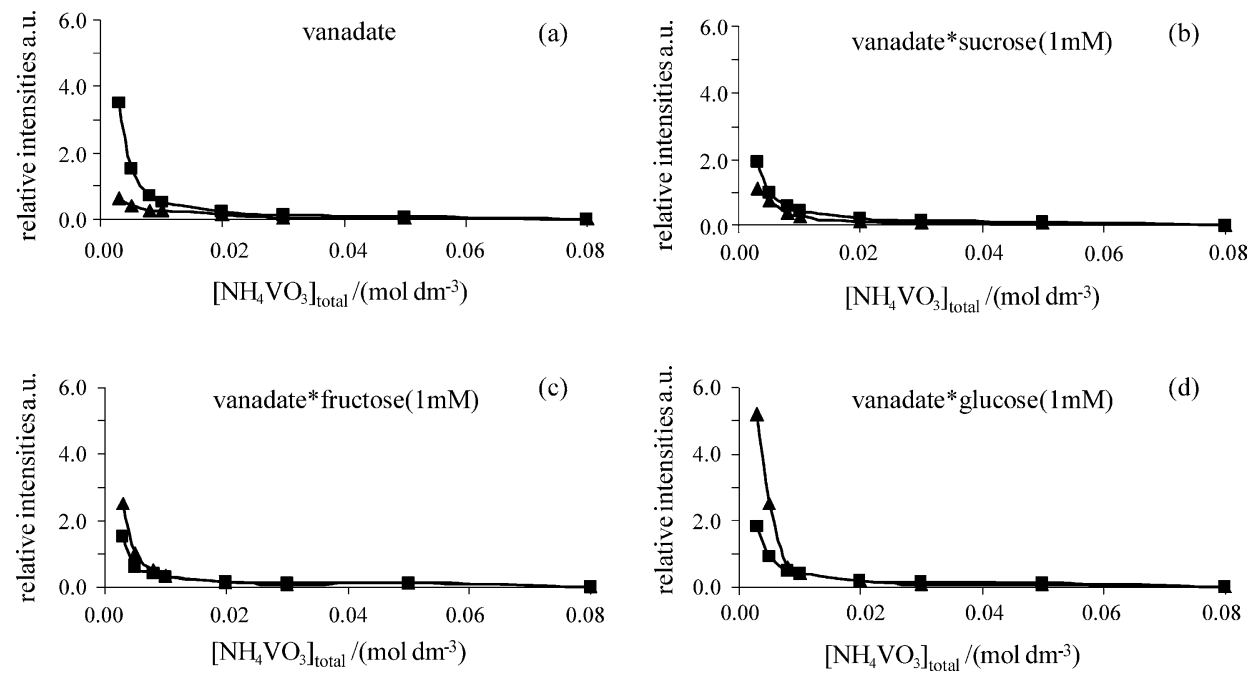

Fig. 5. Plot of the relative intensity $I_{830} / I_{930}(\mathbf{\square})$ and $I_{830} / I_{945}(\boldsymbol{\Delta})$ ratio in: (a) vanadate-water, (b) vanadate-water-sucrose, (c) vanadate-water-fructose and vanadate-water-glucose solutions.

vanadium total concentrations, in the presence of $1 \times 10^{-3} \mathrm{M}$ sucrose. Fig. 5 shows the plot of the relative Raman intensities $I_{830} / I_{930}$ and $I_{830} / I_{945}$ as a function of the total vanadium concentration for the four types of vanadate species in aqueous solution (vanadate-water, vanadatewater-sucrose, vanadate-water-fructose and vanadatewater-glucose).

From the spectral changes shown in Fig. 4 it appears that the major species are HV2, V3L, V4L and V4C over the whole concentration range studied. However, for a total vanadium concentration below $10 \mathrm{mM}$ the broad spectral feature centred at $c a .830 \mathrm{~cm}^{-1}$ becomes significant. This spectral effect resembles that observed with pure aqueous vanadate solutions (this work and Ref. [3]) and suggests, as would be expected from simple equilibrium considerations, that dilution leads to an increase of the relative amount of the smaller vanadate species (e.g. V1, HV1 and V2).

This effect was found to be independent on the carbohydrate used (glucose, fructose or sucrose). However, observation of the data in the plots shown in Fig. 5 show some differences: (i) in simple aqueous vanadate solution, the increase of the $830 \mathrm{~cm}^{-1}$ relative intensity occurs mainly at the expense of a decrease of the relative intensity of the shoulder at $930 \mathrm{~cm}^{-1}$; (ii) in the presence of $1 \mathrm{mM}$ of glucose the intensity increase of the $830 \mathrm{~cm}^{-1}$ band is mainly associated with a decrease of the $945 \mathrm{~cm}^{-1}$ band; (iii) the solutions containing either fructose or sucrose are between the other two, with both intensity relations being almost equally affected. From these observations it can be concluded that the stability of the oligomeric species are dependent on the type of carbohydrate present in solution. Upon the addition of the carbohydrate to the aqueous vanadate solutions, the stability of the linear HV2, V3L and V4L species decreases in the following order fructose $>$ sucrose $\approx$ glucose $>$ no-carbohydrate, whereas, the stability of the cyclic forms (less-charged than the linear congeners) follows the different stability order, no-carbohydrate $>$ sucrose $>$ fructose $>$ glucose.

\section{4. $\mathrm{NMR}$ spectra of $\mathrm{NH}_{4} \mathrm{VO}_{3}$ in aqueous solutions} of sucrose, fructose and glucose

The ${ }^{51} \mathrm{~V}$ NMR spectrum of a solution of $\mathrm{NH}_{4} \mathrm{VO}_{3}$ (30 mmol dm ${ }^{-3}, \mathrm{pH}^{*} 7$ ) in $\mathrm{D}_{2} \mathrm{O}$ shows four signals that can be assigned to tetrahedral monovadate, divanadate, tetravanadate and pentavanadate species [22]

In the presence of sucrose $(30 \mathrm{mM})$, the equilibrium between oligomeric species is slightly changed and besides the tetrahedral monovadate, divanadate, tetravanadate and pentavanadate in a ${ }^{51} \mathrm{~V}$ NMR spectrum of a solution of $\mathrm{NH}_{4} \mathrm{VO}_{3}$ /sucrose 30:30 $\mathrm{mM}\left(\mathrm{pH}^{*} 7\right)$ in $\mathrm{D}_{2} \mathrm{O}$, it is possible to assign two complex species in very small concentrations, a $(\delta=-538 \mathrm{ppm})$ and $\mathbf{b}(\delta=-552 \mathrm{ppm})$. Species $\mathbf{a}$ and $\mathbf{b}$ are also detected in the ${ }^{1} \mathrm{H}$ NMR spectra but their low concentration precludes their detection in the ${ }^{13} \mathrm{C} N M R$ spectrum.

Changing from sucrose to glucose the results are very similar. In the ${ }^{51} \mathrm{~V}$ NMR spectrum of a $\mathrm{D}_{2} \mathrm{O}$ solution of $\mathrm{NH}_{4} \mathrm{VO}_{3} /$ glucose 30:30 mM (pH* 7), two complex species in very small concentrations, $\mathbf{c}(\delta=-524 \mathrm{ppm})$ and $\mathbf{d}$ $(\delta=-530 \mathrm{ppm})$ are detected in addition to the tetrahedral

Table 4

Assignment of the Raman bands of vanadate aqueous solutions

\begin{tabular}{ll}
\hline Raman shift $\left(\mathrm{cm}^{-1}\right)$ & Vanadate species $(\mathrm{V} n)^{\mathrm{a}}$ \\
\hline $790-880$ & V1, HV1, V2 \\
930 & HV2, V3L, V4L, V5L, V6L \\
945 & H2V1, V3C, V4C, V5C, V6C \\
\hline
\end{tabular}

${ }^{\text {a }} n$, stands for the number of vanadium centres; $\mathrm{L}$ and $\mathrm{C}$, linear and cyclic, respectively. 
Table 5

Concentrations of vanadate species obtained from ${ }^{51} \mathrm{~V}$ NMR at $298.15 \mathrm{~K}$

\begin{tabular}{lcccccc}
\hline & $\mathrm{V} 1$ & $\mathrm{~V} 2$ & $\mathrm{~V} 4$ & $\mathrm{~V} 5$ & $\mathrm{~V} 10$ & $C_{\mathrm{t}}$ \\
\hline $\mathrm{NH}_{4} \mathrm{VO}_{3}{ }^{\mathrm{a}}$ & 0.7 & 1.3 & 24.6 & 3.4 & - & - \\
$\mathrm{NH}_{4} \mathrm{VO}_{3} /$ sucrose $^{\mathrm{b}}$ & 1.5 & 2.4 & 22.9 & 2.2 & - & 1.0 \\
$\mathrm{NH}_{4} \mathrm{VO}_{3} /$ glucose $^{\mathrm{b}}$ & 1.4 & 3.2 & 20.2 & 3.4 & 0.6 & 0.6 \\
\hline
\end{tabular}

The concentration of all the vanadate species are shown as vanadium atom concentration in $\mathrm{mm} \mathrm{dm}{ }^{-3}$ units and are obtained the ${ }^{51} \mathrm{~V}$ integrals. Ionic strenght was not controlled. V1, monomeric vanate; V2, dimeric vanadate; V4, tetrameric vanadate; V5, pentameric vanadate; V10, decameric vanadate; $C_{t}$, is the amount of vanadium complexes with glucose or sucrose (in atoms of vanadium).

a $30 \mathrm{mmol} \mathrm{dm}^{-3}$ solution, $\mathrm{pH}^{*} 7$ (p. 3)

b $30: 30 \mathrm{mmol} \mathrm{dm}^{-3}$ solution, $\mathrm{pH}^{*} 7$ (p. 3).

monovadate, divanadate, tetravanadate, pentavanadate and small amounts of decavanadate [22,23].

Changing from sucrose to fructose, extensive reduction of $\mathrm{V}(\mathrm{V})$ to $\mathrm{V}(\mathrm{IV})$ occurs, as seen by colour formation in the solution, and this leads to severe line broadening of the signals [24].

As shown in Table 5, when sucrose or glucose is added to a solution of vanadate, the dominant species, V4, slightly decreases in concentration in favour of $\mathrm{V} 1$ and $\mathrm{V} 2$ and the minor complex species $\mathbf{a}, \mathbf{b}, \mathbf{c}$ and $\mathbf{d} .{ }^{51} \mathrm{~V}$ chemical shifts of species $\mathbf{a}$ and $\mathbf{b}$, formed with sucrose, suggest the presence of octahedral metal centres, whereas $\mathbf{c}$ and $\mathbf{d}$, detected with glucose, are probably 2:2 (metal:ligand) complexes possessing trigonal bipyramidal centres.

The complexation of vanadate (V) with glucose has previously been studied by Geraldes et al. [25] and our results agree with those found by these authors. However, we propose, in agreement with more recent literature [26], that the two complexes found with $\mathrm{V}(\mathrm{V})$ and glucose are probably 2:2 (metal:ligand) complexes possessing trigonal bipyramidal centres, with the ligand complexing with the metal through the vicinal $(1,2)$ cis-diol group of the $\alpha_{\mathrm{p}}$ and $\alpha_{\mathrm{f}}$ forms of glucose.

The complexes formed with sucrose are probably octahedral species [25] and the coordination sites of the ligand may involve $\mathrm{OH}$ groups from the two moieties of the sugar molecule.

\section{Conclusions}

We have measured diffusion coefficients, electrical conductivity, and obtained Raman and NMR spectral data for ammonium monovanadate in aqueous solutions of sucrose, and its structural units fructose and glucose, at 298.15 K to obtain structural information on these systems. In the presence of sucrose and glucose, the diffusion behaviour of ammonium monovanadate can be explained by formation of two complexes in small concentrations (Table 5). These species are suggested to be responsible by the increase of the free energy gradient driving the diffusion process. With fructose, the diffusion behaviour is complicated by extensive reduction of $\mathrm{V}(\mathrm{V})$ to $\mathrm{V}(\mathrm{IV})$.

Formation of oligomeric species is shown by ionic conductivity measurements, and is supported by Raman spectral studies. From the conductivity data, critical oligomeric concentrations are determined and in agreement with those obtained by Raman analysis to the same systems. ${ }^{51} \mathrm{~V}$ and ${ }^{1} \mathrm{H}$ NMR spectral studies confirm complexing of the vanadium (V) species by sucrose and glucose, and show the presence of a variety of species, with octahedral species dominant in the case of sucrose, while 2:2 complexes, having trigonal bipyramidal structures are suggested to be present in the case of glucose.

\section{Acknowledgements}

We are grateful to POCTI, FCT, FEDER for financial support through the projects POCTI/QUI/39593/2001 and POCTI/35415/QUI/2000. We also thank the Fundação para a Ciência e a Tecnologiafor funding through the Centro de Química (ACFR, AJMV, VMML, EFGA, HDB), Unidade de Química-Física Molecular(AMA and AMAC) and Unidade Espectroscopia RMN (MLR).

\section{References}

[1] Z. Meyerovitch, J. Farfel, Y. Sack, Schechter, J. Biol. Chem. 262 (1987) 6658.

[2] Y. Shechter, A. Shisheva, R. Lazar, J. Libman, A. Shanzer, Biochemistry 31 (1992) 2063.

[3] A.M. Amado, M. Aureliano, P.J.A. Ribeiro-Claro, J.J.C. Teixeira-, Dias, J. Raman Spectrosc. 24 (1993) 699.

[4] P.J.A. Ribeiro-Claro, A.M. Amado, J.J.C.T. Dias, J. Comp. Chem. 17 (1996) 1183.

[5] J.N. Agar, V.M.M. Lobo, J. Chem. Soc., Faraday Trans. 171 (1975) 1659.

[6] J. Barthel, F. Feuerlein, R. Neuder, R. Wachter, J. Sol. Chem. 9 (1980) 209

[7] V.M.M. Lobo, Handbook of Electrolyte Solutions, Elsevier, Amsterdam, 1990.

[8] V.M.M. Lobo, Pure Appl. Chem. 65 (1993) 2613.

[9] V.M.M. Lobo, A.C.F. Ribeiro, M.P. Veríssimo, Ber. Buns. Phys. Chem. 98 (1994) 205.

[10] V.M.M. Lobo, A.C.F. Ribeiro, L.M.P. Veríssimo, J. Chem. Eng. Data 39 (1994) 726.

[11] V.M.M. Lobo, A.C.F. Ribeiro, S.G.C.S. Andrade, Ber. Buns. Phys. Chem. 99 (1995) 713.

[12] A.C.F. Ribeiro, PhD thesis, Coimbra (1999). V.M.M. Lobo, A.C.F. Ribeiro, L.M.P. Verissimo, J. Mol. Liquids 78 (1998) 139.

[13] A.C.F. Ribeiro, V.M.M. Lobo, E.F.G. Azevedo, M.G. Miguel, H.D. Burrows, J. Mol. Liquids 94 (2001) 193.

[14] A.C.F. Ribeiro, V.M.M. Lobo, E.F.G. Azevedo, J. Sol. Chem. 30 (2002) 1111.

[15] A.C.F. Ribeiro, V.M.M. Lobo, E.F.G. Azevedo, M.G. Miguel, H.D. Burrows, J. Mol. Liquids 102 (2003) 285.

[16] V. Martorana, L. La Fata, D. Bulone, P.L. San, Biagio, Chem. Phys. Lett. 329 (2000) 221. 
[17] L. Onsager, R.M. Fuoss, J. Phys. Chem. 36 (1932) 2689.

[18] B. Jönsson, B. Lindman, K. Holmberg, B. Kronberg, Surfactants and Polymers in Aqueous Solution, Wiley, England, 1998.

[19] Y. Moroi, N. Yoshida, Langmuir 13 (1997) 3909.

[20] N.D. Chasteen, Structure and Bonding 53 (1983) 105.

[21] D. Rehder, in: H. Sigel, A. Sigel, M. Dekker (Eds.), Metal Ions in Biological Systems, New York, vol. 31, 1995.
[22] D. Rehder, Coord. Chem. Rev. 182 (1999) 297.

[23] C.J. Besecker, W.G. Klemperer, D.J. Maltibie, D.A. Wright, Inorg. Chem. 24 (1985) 1027.

[24] Z. Khan, P.S.S. Babu, K-ud-Din, Carbohydrate Res. 339 (2004) 133.

[25] C.F.G.C. Geraldes, M.M.C.A. Castro, J. Inorg. Biochem. 35 (1989) 79

[26] J.-F. Verchère, S. Chapelle, F. Xin, D.C. Crans, Prog. Inorg. Chem. 47 (1998) 837. 